http://dx.doi.org/10.5007/2175-795X.2013v31n1p337

\title{
Interferências dos órgãos de classe na universidade na perspectiva de advogados, engenheiros e médicos professores
}

Gildo Volpato*

\begin{abstract}
Resumo
O artigo tem como objetivo pesquisar as interferências dos órgãos de classe na universidade e no trabalho realizado pelos professores universitários nos cursos que tradicionalmente formam profissionais liberais. Foram analisadas publicaçôes e entrevistas semi-estruturadas com catorze profissionais liberais professores da área de Direito, Engenharia Civil e Medicina, pertencentes a três universidades catarinenses. $\mathrm{O}$ estudo revelou que os órgãos de classe criticam a expansão dos cursos pela falta de qualidade, mas, também, pela reserva de mercado. Os órgãos de classe exercem influência na docência, especialmente pela posição desses frente às políticas de expansão, bem como na definição do perfil da formação.
\end{abstract}

Palavras-chave: Universidade. Professor universitário. Entidade de classe.

*Doutor em Educação pela Universidade do Vale do Rio dos Sinos (UNISINOS). Professor da Unidade Acadêmica de Humanidades, Ciências e Educação (UNAHCE) e do Programa de Pós-Graduação em Educação da Universidade do Extremo Sul Catarinense (UNESC). 


\section{Introdução}

É preciso que a ideia de autonomia universitária, de liberdade acadêmica por parte dos professores nas mudanças de matrizes curriculares e de práticas pedagógicas em cursos de tradicional formação acadêmica e profissional seja, no mínimo, relativizada e olhada de forma crítica. A clássica afirmaçáo de Marx (1978) de que os homens fazem, eles mesmos, sua história, mas num meio determinado que os condiciona, parece encontrar sintonia nessa relação. A relação entre as ideias e os processos sociais que as sustentam é sempre uma relação dialética.

A universidade está situada em um contexto mais amplo da sociedade que influencia seu fazer cotidiano. Além deste contexto maior da sociedade, os professores universitários sofrem interferências advindas do campo profissional e da própria estrutura do conhecimento educacional.

Conhecer as possíveis interferências na atuação dos professores universitários, advindas do campo profissional, dos órgãos de classe e da própria estrutura de poder do conhecimento educacional se faz necessário uma vez que eles vivem os conflitos, as tensóes, as exigências e as expectativas oriundas de ambas as atividades.

Partindo desse entendimento é que desenvolvi um estudo onde procurei compreender como os profissionais liberais, que são também professores universitários, relacionam-se com seus órgãos de classe, bem como suas representaçóes acerca do papel que estes deveriam desenvolver em relação à universidade. Da mesma forma, mais especificamente, busquei verificar se as expectativas do campo profissional e dos órgãos de classe sobre a formação acadêmica impactam o docente que é também profissional liberal.

O estudo envolveu cursos que tradicionalmente formam profissionais liberais: Direito, Engenharia Civil e Medicina, pertencentes a três universidades catarinenses. A pesquisa foi de cunho etnográfico, com abordagem qualitativa a partir de análise documental e entrevistas semi-estruturadas com catorze professores: cinco de Engenharia Civil, cinco de Medicina e quatro de Direito, apontados pelos alunos formandos, por meio de questionários, como referência na docência em seus respectivos cursos de graduação. Os documentos analisados, por serem os mais lidos pelos professores indicados, foram as Revistas da Ordem dos Advogados do Brasil (OAB/SC), os Boletins do Conselho Regional de Engenharia e Arquitetura (CREA/SC), as Revistas do Conselho Federal de 

médicos professores

Engenharia e Arquitetura (CONFEA), que foram publicadas entre 2002 a 2005, e os Boletins do Conselho Regional de Medicina (CREMESC), publicados de 2005 a 2006.

\section{Questões históricas e conceituais}

$\mathrm{Na}$ medida em que os grupos profissionais foram se agregando e constituindo organizaçōes e conselhos de profissóes, aumentaram as tensóes entre estes e as instituiçóes formadoras. Passaram os conselhos, por sua vez, a exercer um comportamento de controle que muitas vezes extrapola o da fiscalização da atuação do profissional.

Essas relaçóes, estabelecidas no seio da sociedade e evidentes no espaço da universidade, são frutos de uma longa história partilhada e construída pelos agentes sociais. $\mathrm{O}$ homem procura formas de organizar sua vida, conforme suas necessidades e do grupo social. Berger e Luckmann (1985) nos ajudam a compreender o que são essas relaçóes estabelecidas, envolvendo o ambiente e o meio social, que permitem aos seus agentes um conjunto de açóes habituais compartilhadas, dando origem às instituiçóes. Portanto, estas são produtos históricos e culturais que interferem na conduta humana, estabelecendo padróes previamente definidos, favorecendo rumos em uma direçáo por oposiçáa às muitas outras teoricamente possíveis.

Conforme os autores são as instituições como a escola, a família e o exército, por exemplo, que "produzem" indivíduos por meio das relaçôes de força que se estabelecem na sociedade (BERGER; LUCKMANN, 1985). No entanto, o homem, além de ser produzido, é produtor do mundo. A atividade humana e os seus significados devem ser entendidos produzindo o mundo e não sendo produto da natureza das coisas.

Cada instituição e cada grupo social se organizam conforme seus condicionantes socioculturais. A própria ordem social existe, unicamente, como produto da atividade humana.

Não é possível atribuir-lhe qualquer outro status ontológico sem ofuscar irresistivelmente suas manifestações empíricas. Tanto em sua gênese (ordem social resultante da atividade humana passada) quanto em sua existência em qualquer instante do tempo (a ordem 
social só existe na medida em que a atividade humana continua a produzi-la) ela é um produto humano. (BERGER; LUCKMANNN, 1985, p. 76).

Uma tipificação recíproca de ações habituais por tipos de atores só pode acontecer por meio de uma instituição que lhe dá condiçẫo para sua constituição. Para que essas açóes sejam sempre partilhadas, precisam ser acessíveis a todos os membros do grupo social particular em questão, e a própria instituição tipifica tanto os atores individuais como as açôes individuais. "No curso de sua interação estas tipificaçôes serão expressas em padrôes específicos de condutas" (BERGER; LUCKMANNN, 1985, p. 82). Nesse sentido, dizer que um segmento da atividade humana foi institucionalizado é dizer, em certa medida, que esse segmento foi submetido ao controle social.

Percebe-se, a partir das contribuiçóes de Berger e Luckmann (1985), que uma dada ordem social precede qualquer desenvolvimento individual orgânico. Essa qualidade é a objetividade. Isso significa dizer que as instituiçôes hoje existentes frequentemente são experimentadas como existindo para além dos indivíduos, como se possuíssem uma realidade própria. Um mundo institucional, por conseguinte, apesar de ser uma objetividade produzida e construída pelo homem, é experimentado por ele mesmo como realidade objetiva: "Apesar da objetividade que marca o mundo social na experiência humana ele não adquire por isso um status ontológico à parte da atividade humana que o introduziu [...]" (BERGER; LUCKMANN, 1985, p. 87).

As estruturas objetivas que dão forma, conteúdo e identidade às instituições existem independentemente da consciência e da vontade dos agentes. Ao mesmo tempo, como bem aponta Bourdieu (1983), a açáo dos agentes no espaço social (em diferentes campos de atuação) influencia essas estruturas, podendo até modificá-las em longo prazo.

Não adianta um sujeito singular dizer que quer viver e construir um mundo livremente. As estruturas estáo aí e se póem sobre cada um dos sujeitos históricos, produzindo impactos, gerando conflitos, condicionando as açóes e os pensamentos, configurando as relações socialmente distribuídas. É a história objetivada nas coisas, é o que aparece objetivamente, o que é exteriorizado, é o campo, como diz Bourdieu (1983). Sáo esferas da vida social que se automatizam progressivamente e que, portanto, passam a ser consideradas como algo natural, algo dado. A história se transforma em campo sempre que ela se 

médicos professores

automatizar de outras esferas sociais, ao mesmo tempo em que sua existência torna-se cristalizada.

O campo é o espaço social onde as posições dos agentes se encontram a priori fixadas. No entanto, Bourdieu (1988) considera o campo, ao mesmo tempo, como um campo de forças e campo de lutas, que visam a transformar esse campo de forças. As forças variam de acordo com as posições que os agentes ocupam e pelas lutas que acontecem de forma interativa ou conflitiva, levando à conservação ou transformação do campo. Nesse sentido, a posição dos agentes em determinados campos sociais vai depender da posse de grandezas de capitais. Portanto, o campo se particulariza, pois, como um espaço onde se manifestam relações de poder, se estrutura a partir da distribuição desigual de um quantum social que determina a posição que um agente específico ocupa nesse espaço. Bourdieu (1988) denomina esse quantum de "capital social”. Quem detém mais capital (econômico, cultural, simbólico etc.), detém mais poder. No caso da ciência, o capital social, o quantum se refere à autoridade científica. A luta que se trava entre os agentes é uma disputa em torno da legitimidade da ciência. $\mathrm{O}$ pesquisador que desfruta de posições hierarquicamente reconhecidas como dominantes dispóe de maior capital científico e possui individualmente maior celebridade e prestígio. Nesse sentido, o campo, no âmbito da academia, se define como o lócus onde se trava uma luta concorrencial entre os atores em torno do reconhecimento de sua autoridade científica.

$\mathrm{Na}$ estrutura objetiva do campo, os indivíduos adquirem um corpo de disposiçôes, que lhes permite agir de acordo com as possibilidades existentes no interior dessa estrutura objetiva. A isso Bourdieu (1983) chama de habitus, pois, para ele, funciona como uma força conservadora no interior da ordem social. É como se a história estivesse encarnada nos corpos, estivesse interiorizada, fazendo com que os agentes pensem, falem e se movimentem de determinados modos.

$\mathrm{O}$ autor se refere ao habitus com o seguinte conceito:

Sistema de disposições duráveis, estruturas estruturadas predispostas a funcionarem como estruturas estruturantes, isto é, como princípio que gera e estrutura as práticas e as representaçóes que podem ser objetivamente "regulamentadas" e "reguladas" sem que por isso sejam o produto de obediência de regras, objetivamente adequadas a um fim, sem que se tenha necessidade da projeção consciente deste fim ou do domínio das 
operaçóes para atingi-lo, mas sendo, ao mesmo tempo, coletivamente orquestradas sem serem produto da ação organizadora de um maestro. (BOURDIEU; PASSERON, 1982, p. 175).

O habitus tende a conformar, a orientar a ação dos agentes e, sendo produto das relaçôes sociais, assegurar a reprodução dessas mesmas relaçôes objetivas que o engendram. Ele se apresenta como social e individual. Refere-se a um grupo ou a uma classe, mas também ao elemento individual. $O$ processo de interiorização implica sempre a internalização da objetividade, o que ocorre, certamente, de forma subjetiva, mas que náo pertence exclusivamente ao domínio da individualidade. A relativa homogeneidade dos habitus subjetivos (seja de classe, de grupo, ou outras) encontra-se assegurada na medida em que os indivíduos internalizam as representaçôes objetivas segundo as posiçôes sociais que assumem e efetivamente desfrutam. O que garante a adequação entre as açōes dos sujeitos e a realidade objetiva da sociedade é a interiorização pelos atores dos valores, normas e princípios sociais.

É nesse mesmo sentido que Popkewitz (1991) afirma que a conduta dos sujeitos se estrutura segundo códigos da cultura que determinam a forma como as pessoas pensam, sentem, vêem e atuam nos espaços sociais.

Os capitais são sempre relacionais. O sujeito vai incorporando o habitus que o permite acumular capitais. $\mathrm{O}$ acúmulo de capitais permite a ampliação de ação dos agentes nos campos. Contudo, só é possível interiorizar na medida em que o agente passa a ter contato com o capital próprio da linguagem do campo, pois ele é de domínio de quem o frequenta. Bourdieu (1983) afirma que para o ator social tentar ocupar um espaço é necessário que ele conheça as regras do jogo dentro do campo social e que esteja disposto a jogar. Conforme transitam, frequentam o campo, os atores irão aprendendo a agir, selecionar, perceber, fazer, pensar e se expressar desse lugar, ou seja, vão adquirindo o habitus.

\section{O papel dos órgãos de classe na perspectiva dos professores}

Participar de um órgão de classe é uma obrigação na sociedade atual, principalmente para os profissionais que atuam numa profissão regulamentada, como é o caso de advogados, médicos e engenheiros.

Todos os professores pesquisados estão registrados em seus respectivos 

médicos professores

órgãos de classe. Os quatro professores dos cursos de Direito participam da $\mathrm{OAB}$, e um deles participa, também, da Associação Catarinense do Ministério Público. Quanto à atuação junto à $\mathrm{OAB}$, três se limitam a contribuir com a anuidade e um já foi atuante.

Uma das questóes que, de certa forma, coloca em cheque a atuação da universidade e sua autonomia na formação de futuros profissionais é a prova da Ordem dos Advogados do Brasil. Os quatro professores do Curso de Direito, em entrevista, defenderam implícita ou explicitamente o exame da OAB como critério para entrar no mercado de trabalho, ao mesmo tempo em que fazem críticas a quantidade e a falta de qualidade de muitos cursos de Direito, sem adentrar nas especificidades dos cursos em que atuam como podemos perceber no depoimento a seguir:

A OAB está tentando cobrar um padrão de formação que todos os cursos de Direito deveriam ter. A figura do advogado hoje tem uma carga pesada pelos maus profissionais que sairam no mercado [...]. Acho que essa prova faz uma seleção que a graduação não faz. (Professor 1 do Direito).

Os argumentos utilizados pelos professores em favor do Exame da Ordem, embora mencionem a quantidade e a falta de qualidade de muitos cursos de Direito, referem-se, em última instância, à preocupação com a reserva de mercado. Nota-se que a Instituição, neste caso a $\mathrm{OAB}$, criou uma condição que parece estar acima dos sujeitos responsáveis pela formação dos futuros operadores do Direito, ou seja, os professores universitários, que também são da área.

Uma das revistas analisadas trouxe uma reportagem sobre os resultados de uma pesquisa quantitativa realizada recentemente com profissionais registrados na $\mathrm{OAB} / \mathrm{SC}$, a qual aponta que nem todos os advogados concordam com o exame da OAB: "Quanto ao Exame da Ordem, a maioria dos advogados considera-o de bom nível e atingindo seus objetivos, porém, um terço dos entrevistados não compartilha totalmente dessa aprovação [...]" (PERFIL, 2006, p. 13).

O Exame da Ordem também tem sido discutido do ponto de vista dos conteúdos que privilegia e dos que ela silencia, demonstrando uma luta concorrencial (BOURDIEU, 1983), entre diferentes abordagens e princípios 
filosóficos/epistemológicos. De um lado aparecem os que defendem o Direito Dogmático, o da técnica, da norma e o da regra, e de outro os simpatizantes e defensores do Direito Alternativo, que leva em conta as dimensões éticas, históricas e culturais na aplicação de qualquer princípio do Direito. Um professor falou da falta de diálogo e discordância entre duas comissóes internas da OAB de Santa Catarina, principalmente em relação as questões das provas aplicadas nos exames:

A Comissão de Ensino Jurídico defende questöes sociológicas, filosóficas, históricas, a formação do cidadão como um todo e não única e exclusivamente norma. No entanto a Comissão do Exame da ordem, só elabora questóes de normas que estâo no Código Civil, onde o candidato tem que decorar. (Professor 2 do Direito).

Para dois professores, além do Exame da Ordem a OAB poderia contribuir com avaliações de projetos e na definição do perfil esperado dos futuros profissionais que a sociedade necessita e espera receber, o que sinaliza uma relativa naturalização em relação à intervenção do órgão de classe na universidade.

Quanto aos cinco professores da Engenharia Civil, todos afirmaram possuir registro no Conselho de Engenharia e Arquitetura (CREA), uma vez que atuaram ou atuam como engenheiros.

Falaram sobre o papel que deve desempenhar o CREA e qual a interface que há, ou que deveria haver, entre o órgão de classe e a universidade. Embora os depoimentos sejam diferentes, os pensamentos são convergentes.

Um deles se limitou a fazer um desabafo sobre o seu descontentamento com a atuação do CREA: "Eu não participo mais de nenhuma reunião do CREA. Na engenharia, a gente se reúne, delibera, decide sobre a tabela de preço, por exemplo, depois cada um corre no mercado competindo do jeito que quiser". (Professor 1 da Engenharia Civil). Outro professor demonstrou ter conhecimento sobre os limites de atuação do órgáo de classe em relaçáo à universidade e apontou para uma ação de co-responsabilidade no sentido de definição de perfil profissional que a sociedade necessita:

O CREA deveria fazer uma análise de demanda de mercado e traçar o perfil do profissional que fosse necessário para supri- 
la. Isso ajudaria a direcionar a formação. Essa informação seria interessante, mas a questão da formação do profissional a própria universidade deve se encarregar. (Professor $2 \mathrm{da}$ Engenharia Civil).

No entanto, três deles defenderam a posição de que o CREA deveria ter uma atuação maior no âmbito da universidade. Acreditam ainda que, interagindo com a universidade, estaria contribuindo com uma formação mais eficiente, uma vez que opinariam, inclusive, sobre perfil e grades curriculares como podemos perceber neste depoimento:

O CREA tem papel importante no aprimoramento dos profissionais já formados, mas acho que tem pouco relacionamento com as universidades. Eles poderiam fiscalizar em relação ao cumprimento de carga horária minima, para dar habilitação para determinadas atividades da engenharia civil. Ver se a matriz está atualizada. (Professor 3 da Engenharia Civil).

Percebe-se, também, no âmbito da Engenharia Civil um processo crescente de aceitação e de expectativa por parte dos professores de que haja maior intervençáo do órgão de classe nos cursos de graduação.

A ideia de uma prova de entrada na profissão encontra guarida no pensamento de um dos professores entrevistados, manifestada dessa forma: "Inclusive, sou a favor de que o CREA aplique um exame, tipo o da OAB. Eu sou a favor de fazer uma prova também." (Professor 4 da Engenharia Civil).

Em relação aos professores dos Cursos de Medicina, todos afirmaram contribuir com o Conselho Regional de Medicina (CRM) e quatro participam também do Sindicato dos Médicos de Santa Catarina. Participar do sindicato da categoria parece ser um diferencial que marca os profissionais dessa área, o que não foi percebido nos dois outros cursos estudados.

Quanto ao papel que deve desempenhar o CRM, todos os entrevistados reconheceram que o controle na abertura de novos cursos é uma grande preocupação: "A relação de hoje é mais de restringir o número de médicos, campo de trabalho. A discussão cai sempre na reserva do mercado e não no como deveriam ser formados." (Professor 1 da Medicina).

Apareceu, nos depoimentos, convergências em relação ao papel do 
CRM em realizar estudos de demandas e de necessidades quanto ao perfil dos futuros profissionais para as diferentes regióes do país, embasando as decisóes das universidades. Um dos nossos entrevistados deixou claro o entendimento da limitação do órgão de classe em relação à universidade:

Deve definir politicas junto com MEC. Definir o perfil do médico a ser formado. Quantos médicos, que tipo de medicina voltada para cada regiāo, mais do que isso eu acho dificil interferir. Mas o que mais fazem é dizer: "Chega de medicina aqui!". Eles fazem esse controle. Não vejo papel para o CRM na docência. Devem interferir no campo profissional, no perfil. (Professor 2 da Medicina).

No entanto, outro entrevistado fez a defesa da interferência do CRM nas universidades, sob a alegação de que ela não tem competência para saber se o aluno tem ou não capacidade para exercer a profissão de médico.

Deveriam interferir não só na formaçāo, mas verificar no final a qualidade dos profissionais se é suficiente ou se precisa fazer complementação. Em qualquer universidade chegam ao final do curso pessoas que não estão capacitadas. A universidade não tem capacidade para perceber se a pessoa tem ou não capacidade para exercer a profissäo, pois tem aspectos da formação que talvez não foram complementados. (Professor 3 da Medicina).

Cabe uma reflexão se são as deficiências nos instrumentos e os critérios de avaliaçáo que não detectam os problemas ou será um acordo não revelado de "promoção automática", pois os alunos já são tratados como colegas médicos pelos próprios professores, como aponta o estudo de Cunha e Leite (1996), uma vez que passaram pelo funil de entrada do vestibular.

O pensamento de que a universidade não tem capacidade para avaliar reforça, no imaginário dos profissionais, a ideia de que o órgão de classe precisa tomar para si esse papel de regulador na entrada da profissáo. Na Medicina também se encontra professores adeptos a ideia de exame:

Foram criadas muitas escolas com a qualidade do ensino médico questionável. Está se formando uma legião de novos médicos que podem somente com o diploma exercer 
Interferências dos órgãos de classe na universidade na perspectiva de advogados, engenheiros e 347 médicos professores

a profissão, sem qualquer outra exigência, residência, especialização. O que seria melhor, em minha opinião, criar um exame de ordem como o dos advogados. Seria uma forma de nós, médicos, regularmos as exigências minimas necessárias para que o jovem médico pudesse exercer a profissão, fiscalizando de forma prática e eficiente o ensino dos cursos de Medicina. (Professor 5 da Medicina).

A defesa de exame de ingresso na profissão pode encontrar razóes alicerçadas no compromisso redobrado que assumem como advogados, engenheiros, médicos e, ao mesmo tempo, como professores, responsáveis pela formação dos novos profissionais.

De qualquer forma, muitos deles atribuem um poder e uma autonomia maior ao órgáo de classe, que congrega os profissionais, do que à autonomia da universidade e à sua própria, enquanto professor universitário. Alguns, pelos depoimentos dados, parecem esquecer seu papel de professor quando falam sobre o órgão de classe. Assumem visivelmente sua identidade como profissionais liberais e não como professores.

O que também se percebe é que apesar de pertencerem a um mesmo grupo, tanto na profissão liberal quanto na docência, nem sempre comungam das mesmas ideias e defendem as mesmas causas em relação ao papel que os órgãos de classe devem ter na sociedade.

\section{Os documentos dos órgãos de classe e as expectativas no perfil da formação}

A partir da ideia de que esses materiais poderiam estar determinando, em certa medida, as representaçóes sobre o papel do órgão de classe em relação à universidade e ao perfil desejado dos profissionais a formar e, por extensão, sugerindo um tipo de docência coerente com a formação esperada, resolvi analisar esses documentos.

Por meio das entrevistas, procurei saber com quais dos materiais publicados pelos órgáos de classe eles mantinham contato permanente e se lembravam de algum tipo de recomendaçáo de como deveria ser o ensino e a docência nos cursos em que atuavam.

As respostas em geral foram no sentido de que não havia nenhuma 
recomendação por parte dos órgãos de classe de como deveria ser o ensino ou docência nos três cursos. Três depoimentos deixaram evidente essa percepção por parte dos professores: "O órgão de classe não faz isso. Ele auxilia o advogado que está entrando para o mercado, mas relacionado a docência a $O A B$ não fala nada". (Professor do Direito); "Os jornais do CREA não falam sobre o ensino, sobre a formação do profissional da área de engenharia civil [...]". (Professor da Engenharia Civil); "Não tem nada no CRM que discute sobre como deve ser o professor. Nenhum boletim ou revista chama atenção a isso. Não dão diretrizes, orientaçóes, não dizem o que deve fazer [...]". (Professor da Medicina).

No entanto, dois professores deixaram entender "nas entrelinhas" que pode ter algo nesse sentido nas revistas, mas que quase náo percebem e talvez não tenham consciência sobre tal fato: "Não explicitamente, mas no fundo você encontra algum indicativo de como deve ser o processo de formação dos advogados". (Professor do Direito); "Dá um toque, mas, o boletim náo fala explicitamente como". (Professor da Medicina).

E assim, muitas vezes de forma sutil é que as representaçóes e as práticas vão se constituindo, ao mesmo tempo em que vão constituindo os sujeitos.

\section{A Revista da Ordem dos Advogados do Brasil de Santa Catarina}

Todos os professores dos Cursos de Direito são assinantes ou têm contatos frequentes com a Revista da OAB/SC. Um dos professores, além da Revista da $O A B$, é assinante da Revista Consulex, específica da área Jurídica. Outro professor, que é também promotor (ou promotor que é também professor), assina a Revista Atuação, do Ministério Público. Pelo critério de maior acesso e leitura escolhi as Revistas da $O A B / S C$ para realizar a análise documental, publicadas nos últimos cinco anos, de 2002 a 2006. A OAB/SC publicou nesse período 19 revistas, que vão do número 105 ao 124 . Das 19 revistas, 15 falam da ou sobre a universidade.

A partir da análise dos depoimentos dos professores e das revistas da $\mathrm{OAB}$ foi possível perceber que houve mudança nas representaçóes sobre a importância de o advogado, médico ou engenheiro possuir formação e titulação de mestre ou doutor para atuar na universidade, principalmente nestes últimos anos pós Lei $n^{\circ}$ 9.394/96, que estabeleceu as Diretrizes e Bases da Educaçáo (BRASIL, 1996). Primeiramente, porque todos os autores de artigos ou depoimentos, ou 

médicos professores

outros profissionais citados, fazem questão de apontar sua formação acadêmica, demonstrando que a titulação possui um valor no campo do Direito. Observem o recorte de duas reportagens: "O autor, que é doutor em Direito pela USP, Mestre em Instituiçôes Jurídico-Públicas pela UFSC [...]” (REVISTA OAB, 2002, p. 21); "O professor [...] conquistou o título de Doutor em Direito junto à UFSC e a tese foi aprovada com distinçâo e louvor" (REVISTA OAB, 2002 , p. 11). As reportagens que falam sobre a avaliação dos cursos pela $\mathrm{OAB}$ apresentam a titulaçáo dos professores como algo importante a ser cobrado das instituiçóes, como pode ser verificado: "No documento constará o número de mestres e doutores do curso, as obras jurídicas e não jurídicas na biblioteca, a grade curricular, o projeto político pedagógico etc.". (REVISTA OAB, 2002, p. 9).

Sem dúvida, o assunto mais debatido e informado aos leitores da Revista é a luta da OAB contra a abertura de novos cursos de Direito no Estado ou o aumento de vagas de cursos já existentes: "As Faculdades de Direito só poderão aumentar a oferta de vagas após consulta ao Conselho Federal da Ordem dos Advogados do Brasil". (REVISTA OAB, 2002, p. 8).

Esse assunto geralmente aparece aliado à crítica da $\mathrm{OAB}$ à falta de qualidade na formaçáo dada pelos cursos de Direito. No entanto, o parâmetro apresentado para reafirmar essa posição é o alto índice de reprovação na prova da OAB. "Muitos cursos de Direito praticam um verdadeiro estelionato educacional ao oferecer ao estudante um ensino jurídico sem qualidade. No Exame da Ordem cerca de 70 \% dos estudantes são reprovados". (MACHADO, 2002, p. 8).

Recentemente a OAB criou o Programa $O A B$ Recomenda e passou a avaliar os cursos de graduação em Direito do país, dentro de critérios próprios, porém em sintonia com exigências do Ministério da Educação (MEC). Como afirma Zanotto (2005, p. 19), Presidente da OAB/SC, "[...] foi criado para funcionar como instrumento de controle e incentivo à melhoria dos padróes de qualidade dos cursos".

Uma das reportagens traz os resultados de uma pesquisa quantitativa realizada recentemente com profissionais registrados na $\mathrm{OAB} / \mathrm{SC}$, que aponta o que os advogados pensam sobre os cursos de Direito e sobre a formação do advogado em Santa Catarina. A pesquisa revelou que

[...] quase a totalidade dos entrevistados considera que os formandos do direito saem parcialmente preparados ou que os cursos universitários estâo fora de sintonia 
com a realidade do mercado, configurando um quadro desfavorável de imagem às instituiçóes que atuam na formação de advogados. (PERFIL, 2006, p. 12).

Com toda essa pressão por parte da $\mathrm{OAB}$, com toda a crítica às faculdades e aos cursos de formação jurídica, os advogados, também professores, podem não se sentir numa posição confortável. Se as revistas não apontam explicitamente uma direção no sentido de caracterizar a docência nos cursos de Direito, no mínimo coloca desafios de que lutem por uma formaçáo de qualidade, pelo menos nos espaços onde eles, também professores, podem intervir. Uma reportagem traz a questáo da formaçáo: "Uma formação jurídica adequada não estará completa sem que o aluno tenha um efetivo e real contato com a vida profissional." (HARGER, 2002, p. 7).

Embora a reportagem, em síntese, faça a crítica aos problemas que podem ocorrer no contato dos alunos com o fórum, aponta a necessidade de leitura da realidade do campo profissional para que haja uma boa formação jurídica. Pode ser um sinal, aos docentes dos cursos de Direito, de que é fundamental, para uma sólida formação, relacionarem teoria e prática, teoria e realidade. $\mathrm{E}$ isso, os professores-referência sabem bem fazer, de acordo com os estudantes.

Outra reportagem sinaliza que os professores do Direito precisam estar constantemente se atualizando, tendo em vista as mudanças do campo: "Os cursos jurídicos não estão acompanhando o desenvolvimento do Direito, cujas normas estáo em constante aperfeiçoamento [...]" (MACHADO, 2002, p. 8).

A questão da ética, demarcada pelos professores nas entrevistas, como algo de muito valor na formação dos futuros profissionais do Direito, também aparece defendida como preocupação da classe em evento da área: "Os advogados catarinenses no XIV Conferência de Advogados da OAB solicitam a inserção, no currículo mínimo, da disciplina específica de ética profissional". (REVISTA OAB, 2002, p. 22).

Talvez a ética, dimensão tão necessária à formação e valorizada tanto por alunos quanto pelos professores, faria mais sentido e teria mais consistência se fosse assumida como um conteúdo transversal no Direito, servindo como pano de fundo às demais disciplinas dos currículos e aos projetos pedagógicos dos cursos. 
Interferências dos órgãos de classe na universidade na perspectiva de advogados, engenheiros e 351 médicos professores

\section{A Revista do CONFEA e o Boletim do CREA/SC}

Os documentos e revistas oficiais que circulam nas mãos dos cinco professores entrevistados da Engenharia Civil são os jornais e boletins do Conselho Regional de Engenharia e Arquitetura de Santa Catarina (CREA/ SC). Além disso, dois recebem a Revista do Conselho Federal de Engenharia e Arquitetura, CONFEA, um a Revista Técnic e, outro, a Revista Concreto, do Instituto Brasileiro de Concreto. Escolhi para análise o Boletim do CREA/SC, publicados entre 2003 e 2006, e a Revista do CONFEA, de 2002 a 2005, serem as mais lidas pelos professores.

Foram analisados 17 boletins do CREA/SC, do número 33 ao 50, e 15 revistas do CONFEA, do número 9 ao 24 . Dos 17 boletins do CREA/ SC, a universidade é citada, de alguma forma, em nove deles. Já na revista do CONFEA, a universidade aparece citada 11 vezes.

As análises me permitiram identificar duas realidades diferentes em relação ao que encontrei nas revistas da $\mathrm{OAB} / \mathrm{SC}$. A primeira refere-se à quantidade de cursos de formaçáo. Enquanto a $\mathrm{OAB}$ luta para regular a abertura de vagas, pela expansão desenfreada que houve dos cursos de Direito, a Revista do CONFEA apresenta um déficit quantitativo de engenheiros no país.

Há poucos engenheiros formados comparado com outros países do oriente como China e Japão, diz Deodete Packer. Segundo o Engenheiro Ênio Padilha, países como Alemanha, França, EUA e Canadá têm 40 ou 50 engenheiros para cada 10 mil habitantes, enquanto no Brasil tem proporcionalmente 15 para cada 10 mil [...]. (CONFEA, 2005, p. 15).

Esse fato já pressupóe que os embates entre os órgãos de classe das Engenharias sejam menores do que os do Direito, tendo em vista que não há, ainda, necessidade de reserva de mercado.

Em outra reportagem, o Presidente do CONFEA, Wilson Lang (2004), traz também a informação do déficit de engenheiros, mas já apresenta a preocupaçáo de que a expansão pode trazer problemas na qualidade da formaçáo.

A educação superior tem passado por algumas reformas importantes. Primeiramente, o déficit quantitativo está 
sendo suprido pela criação de faculdades particulares [...]. O problema deste tipo é que nem sempre as faculdades particulares estão plenamente aptas a formar e qualificar os novos profissionais. (LANG, 2004, p. 31).

Mais uma reportagem aborda o tema da expansão e, em outra, aparece à importância do trabalho realizado pelos engenheiros que participaram da Comissão de Educação do Sistema CONFEA/CREA, em especial na elaboração da proposta de Diretrizes Curriculares das Engenharias.

Outro aspecto que difere do Direito é a posição ou postura que o CONFEA adota diante das universidades e do MEC. Parece ser uma relação de maior cordialidade, de interação, de diálogo e compreensão. Implicitamente, essa relação aparece em vários momentos, principalmente quando a matéria trata de debater mudanças que devem ocorrer nas definiçóes profissionais do sistema.

Com a substituição do currículo mínimo pelas diretrizes curriculares, feita pelo MEC, a Resolução 218 do CONFEA, que define as atribuiçóes profissionais, está condenada à queda ou a uma profunda alteração. Não dá para continuarmos dando atribuiçóes dentro de uma filosofia que era de currículo mínimo, quando hoje existe as diretrizes curriculares, explica Osvaldo Luiz Valiote. (CONFEA, 2002a, p. 33).

Outra reportagem reforça essa intenção do presidente do CREA/SC: "O presidente Zucato falou sobre a importância da integração dos conselhos profissionais com as instituiçóes de ensino, ressaltando que essa é uma das metas da sua gestão." (CREA/SC, 2006, p. 4).

Mesmo havendo uma tendência histórica de tensão e até oposição entre campo profissional e instituição formadora, a intencionalidade pessoal também pode fazer diferença e provocar mudanças na estrutura. Talvez esse seja o caminho escolhido pelo presidente atual. Esse é um exemplo que faz lembrar Bourdieu (1983), quando diz que a ação dos agentes no espaço social (em diferentes campos de atuação) influencia essas estruturas, podendo até modificá-las em longo prazo.

A ideia de um exame de entrada na profissão é veiculada duas vezes, uma na Revista do CONFEA e outra no Boletim do CREA/SC. A revista do 
CONFEA traz o resultado de uma pesquisa feita com os engenheiros que aponta: "Pesquisa realizada pelo coordenador da Comissão de Exercício Profissional (CEP), Reinaldo Sabadotto, mostra que há uma vontade unânime de se fazer um exame e mais um estágio supervisionado, para que somente depois o profissional seria aprovado, o que garantiria sua competência”. (CONFEA, 2002c, p. 38).

Já o Boletim do CREA/SC traz a palavra do presidente, afirmando que, "[...] com exceção do exame da $\mathrm{OAB}$, ainda não existe uma legislação específica que preveja a aplicação do exame para avaliar as demais formações acadêmicas. O assunto é polêmico e a conclusão foi que requer mais discussōes" (ZUCATO, 2006, p. 4).

Sobre como deveria ser ou atuar o docente dos cursos de Engenharia, nada aparece de forma clara e objetiva nas publicaçóes. É nas entrelinhas que devem ser lidas e interpretadas as palavras e as expressōes linguísticas que determinam a construção de certas representaçóes. Interpretei alguns sinais de indicaçóes de conteúdo e/ou forma de como os professores deveriam agir no contexto atual, tendo em vista as mudanças no mundo do trabalho e o surgimento de novas necessidades de atuação profissional. Um "toque" foi dado dessa forma: "É necessária a reformulação dos cursos, para aumentar a capacidade de inserção social e profissional". (CONFEA, 2002b, p. 23).

Há indicação de que o professor deve "estimular a criatividade de novas oportunidades de atuação" (CONFEA, 2003, p. 27) e "estimular o empreendedorismo", como mostra a reportagem abaixo:

Em geral a engenharia está pautada pela segurança total, postura avessa ao empreendedorismo. Durante o processo de formação acadêmica, os engenheiros são supervalorizados pela capacidade técnica de resolução de problemas formatados e não pela capacidade de formatar os problemas [...]. (PADILHA, 2005, p. 16).

Deve também se preocupar com a formação da ética na profissão e com o compromisso com o desenvolvimento sustentável e a responsabilidade social: "Inclusão de disciplinas ligadas à ética e legislação profissional e ao relacionamento da profissáo com o desenvolvimento sustentável nos currículos dos cursos de engenharia, e responsabilidade social" (CONFEA, 2005, p. 13). 
Outro sinal de reorientação curricular e de foco de trabalho dos docentes vem no sentido de estimular o trabalho coletivo/cooperativo. Diz o texto que "[...] a dificuldade também está no perfil desses profissionais [...] não são preparados nas escolas para trabalhar em equipe." (PADILHA, 2005, p. 16). "Em nossa formação não aprendemos a colaborar e sim a competir [...]" (FONSECA, 2004, p. 2).

São críticas e indicaçóes que podem ser interpretadas e internalizadas por professores atentos, sensíveis, comprometidos com a melhoria da qualidade de ensino, de forma a satisfazer as expectativas dos órgãos de classe e exigências do mundo contemporâneo. Talvez sejam "toques" que podem estar interferindo nas práticas usuais na área das Engenharias.

\section{A Revista do Conselho Regional de Medicina de Santa Catarina}

Todos os professores entrevistados dos Cursos de Medicina recebem a Revista do Conselho Regional de Medicina de Santa Catarina, Revista CREMESC. Um deles assina também a revista New England, dois recebem o Jornal Brasileiro de Nefrologia, um tem acesso à Revista Brasileira de Educação Médica e outro, à Revista da Associação Médica Brasileira.

Escolhi para análise as Revistas do CREMESC, publicadas entre 2002 e 2005, e o Boletim CREMESC, de 2005 a 2006, pois são os materiais lidos por todos os professores. Uma pesquisa realizada pelo Conselho Federal de Medicina (CFM), publicada como Trabalho Médico, demonstrou que entre os periódicos mais lidos na regiáo sul destacaram-se o do CFM $(96,5 \%)$ e o do Conselho Regional (92,3\%) (CREMESC, 2005).

Foram analisadas 17 Revistas do CREMESC, do número 82 ao 99, e 10 Boletins CREMESC, do número 1 ao 10. Entre a Revista e o Boletim, são apresentadas 40 reportagens que falam de temas referentes à universidade.

$\mathrm{O}$ assunto com maior recorrência, dando visibilidade aos leitores, são as batalhas do CREMESC contra a abertura de novos cursos de Medicina no Estado de Santa Catarina. São 26 reportagens manifestando posição contrária à criação de novos cursos. Algumas argumentam a falta de condiçôes adequadas das faculdades e em outras há preocupação com a 
qualidade de ensino, bem como com a falta de comprovação da necessidade social ou, ainda, implicitamente, por reserva de mercado: "Na defesa da classe, o fundamental é conseguir conter o desatino na abertura de escolas médicas em todos os estados brasileiros" (ANDRADE, 2002, p. 13).

Nova campanha lançada pelo CFM e a AMB de luta contra a proliferação indiscriminada de novas faculdades de Medicina no país. A campanha tem como Slogan: PROTEJA-SE "Lute pela proibição da abertura de novos cursos de Medicina”. (CREMESC, 2005, p. 6).

Uma reportagem traz os resultados de um trabalho realizado sobre as escolas médicas, Abertura de escolas de Medicina no Brasil: relatório de um cenário sombrio (BUENO; PIERUCINI, 2004), publicado em 2004 pelo Conselho Federal de Medicina (CFM), apresentando dados demonstrativos de que

[...] o Brasil não tem necessidade social de mais cursos de medicina porque tem excessivo número de faculdades mal distribuídas pelo país, assim como na distribuição de profissionais regionalmente. Enquanto a Organização Mundial de Saúde, OMS, recomenda a existência de um médico para atender mil habitantes, no Brasil há uma média de um médico para 622 habitantes. (REVISTA CREMESC, 2004, p. 10).

Também costumam virar notícia os encontros reivindicatórios de entidades médicas, seja no Congresso ou com autoridades de governo, da mesma forma que a participação das entidades médicas na elaboração de instrumentos de avaliaçáo e acompanhamento dos cursos de Medicina do Estado. Além da razáo explícita de buscar melhoria nos cursos, deixam implícito o poder e o prestígio do campo da medicina, como se pode ver de forma clara na reportagem: "Entre os assuntos abordados durante o encontro com o Secretário de Estado de Saúde destacou-se, de maneira especial, a solicitação de apoio ao projeto de lei que visa normatizar e criar critérios para abertura de escolas médicas no território catarinense [...] (REVISTA CREMESC, 2003a p. 12).

Uma reportagem traz a importância de reconhecimento dos diferenciais da profissão de médico, aludindo, principalmente, à dificuldade de ingresso no concorrido vestibular e o longo período de duração da formação. 
Valorizar o médico é reconhecer os diferenciais que cercam a medicina e a sua escolha como profissão. Primeiro é preciso ser aprovado no mais disputado vestibular, cursar a mais longa faculdade (6 anos), ser novamente aprovado e cursar uma ou mais residência(s) e muitas vezes dedicar-se ao mestrado e ao doutorado, que tornaram-se cada dia mais necessário para acompanhar as crescentes exigências da atividade (GERENT, 2006, p. 2).

Se a condição de dificuldade de ingresso deve ser considerada nem por isso deve ser outorgado mais direitos dos demais alunos e profissionais na sociedade.

Além da questão da valorização profissional, aponta para a valorização do mestrado e o doutorado como necessidade atual para os profissionais liberais, o que não ocorria até final da década de 1990, antes da nova Lei de Diretrizes e Bases da Educação Nacional (BRASIL, 1996), como demonstrou os estudos de Cunha e Leite (1996).

Essa mudança em relação a valorizaçáo da titulação pode ser entendida em Bourdieu (1988) quando afirma que, apesar de duráveis, as experiências, costumes e práticas podem, aos poucos, serem modificadas por meio de princípios, chamados por ele de princípios geradores de açôes, que permitem aos agentes buscarem uma multiplicidade de respostas em face das situaçóes em que se encontram quando confrontados a situaçôes habituais. Pode haver transformaçóes quando há um desequilíbrio frequente entre o habitus e as situaçóes em que se encontram, pois o sujeito é levado a modificá-lo para continuar no "jogo" (campo). Quando há desencontro e desconforto, ele tenta se modificar ou modificar a estrutura. Nesse caso, diante da exigência legal e da valorização da titulação dada no âmbito da universidade, tendem a se modificarem.

Essas reportagens também remetem ao alerta de Bourdieu (1983), de que quanto mais recursos científicos acumulados, mais importante será o capital científico incorporado necessário para apropriá-los e ter, assim, direito de acesso aos problemas e instrumentos científicos (métodos científicos) deles decorrentes. Portanto, é possível entender que mais difícil também será a entrada em determinadas profissóes, pois "a principal censura é constituída por esse direito de entrada, isto é, pelas condiçóes de acesso ao campo científico e ao sistema de ensino que a ele dá acesso." (BOURDIEU, 1983, p. 143). 

médicos professores

Para Bernstein (apud DOMINGOS, 1986, p. 149) "a maneira como uma dada sociedade seleciona, classifica, distribui, transmite e avalia o conhecimento educacional que ela considera público reflete a distribuição de poder e os princípios de controle social”.

Sendo assim, quanto maior for o valor atribuído a certos conhecimentos, quanto mais densa e complexa for a estrutura de capital social agregada, maior a dificuldade de acesso a eles, e mais restritiva e classificatória será a sua distribuição e o poder daí advindo.

Essas reflexóes ajudam a compreender porque em determinados cursos de graduação o ingresso é táo concorrido em relação a outros. A expectativa daqueles que conseguem passar pelo portal de entrada deve estar no fato de que, por fazer parte dessa mesma sociedade, percebem, mesmo que de forma pouco consciente, o quanto o conhecimento de determinadas áreas dá acesso à atuação em determinados campos profissionais com valores diferenciados. De certa forma, aumenta assim a possibilidade de alcançar lugares diferenciados na hierarquia de poder e no usufruto dos bens culturais, sociais, políticos e econômicos.

Sobre as expectativas de perfil de docência ou do que valorizam na formação profissional, percebe-se que, no campo da medicina, a dimensão humana da formação é muito valorizada. Duas entrevistas são reveladoras dessa preocupação: "Faz-se necessário ensinar o estabelecimento de vínculos afetivos entre médico e paciente, garantindo a confiança como a base da relação [...]" (REVISTA CREMESC, 2002b, p. 12); "Os médicos do sul, conforme pesquisa do CFM [...] não consideram o poder e o prestígio, e prezam muito mais pela harmonia nas relações inter-pessoais embasadas no respeito e na honestidade" (ARAÚJO, 2005, p. 4).

Aliada à questáo das relaçóes humanas aparece, também, a preocupação com a formaçáo ética, que deve ser dada pelo professor, além da defesa de haver uma disciplina específica.

De modo geral, o médico professor de medicina tem o dever de ensinar ética médica, de vez que é sua obrigação praticá-la [...], observa-se o grande interesse do alunado que transcende os aspectos meramente médicos e chega àqueles do humanismo e da cidadania. Os alunos sentem-se mais responsáveis [...]. (REVISTA CREMESC, 2003a, p. 5). 
Nota-se que o sentido da ética posto na reportagem tem um caráter mais reflexivo do que normativo. Parece não estar se referindo apenas a uma questão de apresentar normas e procedimentos que devem orientar a ação e a relação social, mas assumindo o sentido de reflexão crítica sobre o ethos ${ }^{1}$, como se refere Rios (2000, p. 112). Nesse sentido, a ética assume o seu papel de pensar criticamente sobre a moral enquanto conjunto de valores e princípios orientadores da conduta dos indivíduos e dos grupos sociais. Marina (1996), entende que pode ser recuperado pela ética uma forma moralmente vigente que, ao fundamentá-la, a situaria numa outra lógica que poderia alterar a natureza das coisas, num sentido positivo. Como afirma Rios (2000, p. 118),

[...] é verdade que é da natureza da ética a referência a um dever ser. Mas é também dessa natureza um esforço de transcender um plano restrito e circunstancial, numa perspectiva de totalidade. Esse esforço não tira da ética sua dimensão social e histórica - busca apenas tornar mais preciso seu significado.

A Ética e o cuidado com a dimensão humana, com as relaçôes interpessoais, com a sociedade, com o planeta, são apontados como fundamentais na formação do aluno da medicina. $O$ professor, tendo esse entendimento, pode buscar aperfeiçoamento nessa direção, mas fará bem apenas se encontrar sintonia com o que ele acredita ser fundamental na formação e que seja seu papel enquanto formador. A preocupação com a dimensão ética na formação ficou demonstrada nos três cursos, tanto pelos professores e alunos quanto pelos órgãos de classe.

Balzan (2003), numa pesquisa sobre nível superior de excelência, procurou conhecer as qualidades necessárias ao profissional almejado na perspectiva de estudantes, professores e profissionais de renome nas Ciências Humanas e Ciências Sociais Aplicadas e encontrou fortemente marcada a dimensão ética como um importante valor.

Embora o conhecimento sobre o campo profissional seja um valor inseparável de sua formação específica, seus entrevistados afastam a ênfase dada a um modelo de formação que leve à super-especialização técnica, sob a pressão do mercado. Ao contrário, "[...] ressaltam a necessidade de uma sólida e abrangente formação humanística em consonância com a complexidade do setor em que o formando irá atuar, aliada a prática de pesquisa que encontrem 
soluçóes alternativas para os problemas sociais detectados" (BALZAN, 2003, p.50). Priorizam a formação ético-política sobre a habilitação técnico-científica, o que contraria propostas mercantilistas que, muitas vezes, predominam em universidades brasileiras.

\section{Conclusões}

Quanto à interferência e às expectativas do campo profissional no ensino de graduação e impactos na docência, a pesquisa mostrou que as revistas publicadas pelos órgãos de classe apresentam o que esperam da formação.

No Direito aparece a necessidade de leitura da realidade do campo profissional para que haja boa formaçáo jurídica. Parece ser este um nítido sinal de que é fundamental, para uma sólida formaçáo, os professores relacionarem teoria e prática, teoria e realidade. Sinalizam que os professores do Direito devem se atualizar constantemente, tendo em vista as mudanças de normas e procedimentos do campo. A ética no exercício profissional também aparece como uma preocupaçáo da categoria que deve ser fortemente trabalhada no processo de formação.

Na Engenharia explicita-se a preocupação com a necessidade de reformular os cursos, para aumentar a capacidade de inserção social e profissional dos egressos. Há indicaçáo de que o professor deve estimular a criatividade e o empreendedorismo. Deve também se preocupar com a formação da ética na profissão e com o compromisso, com o desenvolvimento sustentável e a responsabilidade social. Apontam para uma mudança de foco quando afirmam que os docentes devem estimular o trabalho coletivo/cooperativo, uma vez que a competição sempre foi incentivada nessa área.

$\mathrm{Na}$ Medicina, a dimensão humana da formação é muito valorizada. Há sintonia entre o que publicam os órgáos de classe e as expressóes utilizadas pelos professores, como também com as características valorizadas pelos alunos, quando apontam os professores que são referência na docência. As atitudes pessoais, como demonstração de "amor e dedicação aos pacientes", são fortes motivos para a escolha do professor pelos estudantes. Aparece também a importância de uma boa relação interpessoal entre professores e alunos, entre médico e paciente, além da preocupação com uma boa formaçáo ética. $\mathrm{O}$ professor, se encontrar sintonia com o que ele acredita ser fundamental na formação, pode buscar aperfeiçoamento nessa direçáo. 
O reconhecimento de que há problemas em vários cursos de graduação, de que a qualidade da formação nem sempre é a desejada pela sociedade e, às vezes, nem pela própria universidade, é fundamental. Contudo, os problemas da formação devem ser enfrentados pelas próprias universidades, em conjunto com a sociedade, sob pena de que, num futuro próximo, outros campos profissionais venham exigir exames de ingresso no exercício da profissão, tal qual a Ordem dos Advogados do Brasil.

É da universidade o compromisso e a responsabilidade da formação de profissionais para a sociedade, porém ela não pode assumir sozinha essa condição, e nem é responsável por todas as suas dificuldades. A universidade vive a contradição de seu tempo e responde a pressões de um contexto maior da sociedade, talvez esse seja um dos motivos de os órgãos de classe e a própria chamada "lei do mercado" justificarem as incansáveis tentativas de interferir na autonomia universitária.

Portanto, as tensóes entre os órgãos de classe e a universidade tendem a continuar, principalmente pelo fato de que está no imaginário, até mesmo dos profissionais liberais que atuam como professores, o pensamento de que deve haver uma maior interferência de um sobre o outro. É a autonomia universitária colocada em questão pelos próprios profissionais que nela atuam como professores. Talvez isso ocorra pelo fato de estarem vivendo, no dia a dia, um paradoxo permanente. De um lado, como professores, vivenciam a resistência da universidade diante da pressão externa para não perder sua eterna missão de consciência crítica de si mesma e da sociedade, de vanguarda na produção de conhecimentos e na formação profissional. Todavia, de outro lado, como profissionais liberais, acompanham a preocupação dos órgãos de classe com a expansão dos cursos, às vezes pela simples reserva de mercado, porém, em outras, pela baixa qualidade que oferecem e a crítica a um perfil de formação que muitas vezes não corresponde às reais necessidades do mundo do trabalho.

A pesquisa também mostrou que parece haver um pacto de proteção, não consciente e nem revelado, entre os órgãos de classe e os profissionais liberais professores. Os órgãos de classe fazem críticas às universidades e aos cursos de graduação, mas não dirigem aos professores. É como se os professores dos cursos não fossem eles mesmos, os próprios profissionais liberais. Talvez seja uma estratégia atingir as instituiçóes formadoras, os cursos, sem expor os profissionais liberais que neles atuam. 
Os professores, também profissionais liberais, talvez por não terem outra alternativa, procuram conciliar as angústias e críticas dos órgãos de classe, trazendo as experiências do campo profissional para a universidade. A maioria dos pesquisados procura realizar um trabalho decente e coerente articulando o que o campo necessita, a universidade deseja e o que eles acreditam.

\section{Nota}

${ }^{1}$ Ethos designa o espaço da cultura, do mundo transformado pelos seres humanos, onde ganha o sentido de costume, jeito específico de viver dos seres humanos e que, exatamente por transcender a natureza, é plural, reveste-se de uma configuração diferente nas sociedades. (RIOS, 2000, p. 112).

\section{REFERÊNCIAS}

ANDRADE, Edson de Oliveira. Espaço do CFM. Revista CREMESC, Florianópolis, SC, n. 82, p. 13, jan./fev. 2002.

ARAÚJO, Edevard José de. Quem é o médico catarinense? Revista CREMESC, Florianópolis, SC, n. 97, p. 4, 2005.

BALZAN, Newton César. Ensino universitário em nível de excelência, limites e possibilidades em duas áreas de conhecimentos: ciências humanas e ciências sociais aplicadas. Revista de Educação PUC, Campinas, SP, n. 15, p. 39-53, nov. 2003.

BERGER, Peter; LUCKMANN, Thomas. A construção social da realidade. Petrópolis, RJ: Vozes, 1985.

DOMINGOS, Ana Maria et al. A teoria de Bernstein em sociologia da educação. Lisboa: Fundação Calouste Gulbenkian, 1986.

BOURDIEU, Pierre. O campo científico. In: ORTIZ, Renato (Org.). Sociologia. São Paulo: Ática, 1983. p. 122-155.

BOURDIEU, Pierre. Liçôes de aula. São Paulo: Ática, 1988.

BOURDIEU, Pierre; PASSERON, C. A . A reprodução: elementos para uma teoria da sociedade. Rio de Janeiro: Alves, 1982.

BRASIL. Lei n ${ }^{\circ}$ 9.394/96, de 20 de dezembro de 1996. Estabelece as diretrizes e bases da educação nacional. Diário Oficial da União, Brasília, 
DF, 23 dez. 1996. Disponível em: <portal.mec.gov.br/setec/arquivos/pdf1/ proejalei9394.pdf>. Acesso em: 17 maio 2006.

BUENO, Ronaldo Rocha L.; PIERUCINI, Maria Cristina. Abertura de escolas de medicina no Brasil: relatório de um cenário sombrio. Brasília, DF: AMB/CFM, 2004.

CONFEA: Revista. Brasília, DF: Conselho Federal de Engenharia e Agronomia, n. 9, mar./abr. 2002a.

CONFEA: Revista. Brasília, DF: Conselho Federal de Engenharia e Agronomia, n. 10, maio/ jun. 2002b.

CONFEA: Revista. Brasília, DF: Conselho Federal de Engenharia e Agronomia, n. 12, out./dez. 2002c.

CONFEA, Revista. Brasília, DF: Conselho Federal de Engenharia e Agronomia, n. 15, jul./set. 2003.

CONFEA, Revista. Brasília, DF: Conselho Federal de Engenharia e Agronomia, n. 24, out./dez. 2005.

CREA/SC: boletim. Florianópolis, SC: Conselho Regional de Engenharia e Arquitetura de Santa Catarina, n. 50, jan./abr. 2006.

CREMESC: boletim. Florianópolis, SC: Conselho Regional de Medicina de Santa Catarina, 2005. Publicação anual.

CUNHA, Maria Isabel; LEITE, Denise. Decisóes pedagógicas e estruturas de poder na universidade. Campinas, SP: Papirus, 1996.

FONSECA, Celso Ramos. Carta do presidente. CREA/SC, Boletim, Florianópolis, SC, n. 42, p. 2, set./out. 2004.

GERENT, Wilmar de Athayde. Bom senso. CREMESC: boletim, Florianópolis, SC, n. 6, p. 2, maio 2006.

HARGER, Márcio Roberto. Teoria e prática. OAB/SC Revista, Florianópolis, SC, n. 106, p. 7, 2002.

LANG, Wilson. Revista CONFEA, Brasília, DF, n. 19, p. 31, jul./set. 2004.

MACHADO, Rubens Approbato. Curso ruim é estelionato educacional.

OAB/SC Revista, Florianópolis, SC, n. 106, p. 8, maio 2002. 
Interferências dos órgãos de classe na universidade na perspectiva de advogados, engenheiros e 363 médicos professores

MARINA, José A. Ética para náufragos. Lisboa: Editorial Caminho, 1996.

MARX, Karl. O dezoito brumário de Luís Bonaparte. 2a ed. São Paulo, SP: Abril Cultural. 1978. (Coleção Os Pensadores).

PADILHA, Ênio. Missão cumprida. CONFEA: Revista, Braslia, DF, n. 24, p. 16, out./dez. 2005.

PERFIL dos advogados e avaliação da OAB. Revista [da] OAB/SC, Florianópolis, SC, n. 123, p. 12-13, jul. 2006.

POPKEWITZ, Th. S. Ideología y formación social en la educación profesorado. In: POPKEWITZ, Th. S; BEYER, L. E.; ZEICHNER, K. Mitos y realidades en la formación docente. Montevidéo: Edición de la Revista de la Educaión de Pueblo, 1991. (Documentos Pedagógicos).

REVISTA CREMESC. Florianópolis, SC, n. 83, mar./abr. 2002a.

REVISTA CREMESC. Florianópolis, SC, n. 85, jul./ago. 2002b.

REVISTA CREMESC. Florianópolis, SC, n. 86, set./out. 2002c.

REVISTA CREMESC. Florianópolis, SC, n. 90, maio/jun. 2003 a.

REVISTA CREMESC. Florianópolis, SC, n. 92, dez. 2003b.

REVISTA CREMESC. Florianópolis, SC, n. 94, jun. 2004.

REVISTA OAB. Florianópolis, SC: OAB, 2002.

RIOS, Terezinha Azeredo. Por uma docência da melhor qualidade. 2000. Tese (Doutorado em Educação) - Universidade de São Paulo. São Paulo, 2000.

SUPREMO Tribunal de Justiça proíbe novas vagas no curso de Direito. Revista [da] OAB/SC, Florianópolis, SC, n. 106, p. 8, maio 2002.

ZANOTTO, Adriano. Cursos de Direito: a OAB faz alerta para propagandas. Revista [da] OAB, Florianópolis, SC, n. 118, p. 19, maio 2005.

ZUCATO, Raul. Ética é debatida em encontro nacional de conselhos profissionais. Boletim do CREA/SC, Florianópolis, SC, n. 50, p. 4, jan./abr. 2006.

XIV conferência é sucesso de público e conteúdo. Revista [da] OAB/SC, Florianópolis, SC, n. 107, p. 22, dez. 2002. 


\section{Las interferencias de los colegios de profesionales en la universidad a partir de la perspectiva de los professores de derecho, ingeniería y médicos.}

\section{Resumen}

El presente artículo tiene como objetivo investigar las interferencias de los colegios de profesionales en la universidad y en el trabajo realizado por los profesores universitarios en las carreras que tradicionalmente forman profesionales liberales. Fueron alizadas publicaciones $y$ entrevistas semi estructuradas con catorce profesionales liberales en tres universidades catarinenses: profesores de derecho, ingeniería civil y medicina. El estudio reveló que los colegios de profesionales de aula critican la expansión de los curso por falta de calidad, pero también, por la posición frente a las políticas de expansión y por la definición del perfil de formación de estas carreras.

Palabras claves: Universidad. Profesor de la Universidad. Clase de entidad.

\section{Interferences by professional associations in the University from the perspective of professors who are lawyers, engineers and medical doctors}

\begin{abstract}
The purpose of this article is to study the interferences of professional associations in universities and in the work conducted by professors at universities in schools that traditionally educate these professional. A documental analysis of publications was conducted as well as semi-structured interviews with fourteen professionals who are professors in the fields of law, civil engineering and medicine at three universities in Santa Catarina state. The study revealed that the professional organizations criticize the expansion of courses based on a lack of quality, but also to limit the number of professionals in the labor market. The professional agencies exercise influence on the professor, especially in relation to their position concerning expansion policies, and in the definition of the profile of education.
\end{abstract}

Keywords: University. University professor. Professional association.

\section{Gildo Volpato}

E-mail: giv@unesc.net

Recebido em: 5/2/2012

Versão final recebida em: 12/11/2012

Aprovado em: 12/11/2012 